International Journal of Engineering \& Technology, 9(3)(2020) 644-649
International Journal of Engineering \& Technology
SPC
Website: www.sciencepubco.com/index.php/IJET
Research paper

\title{
Case study of liquid suction heat exchanger in a mechanical refrigeration system using alternative refrigerants
}

\author{
Raid Ahmed Mahmood * \\ School of Mechanical and Electrical Engineering, University of Southern Queensland, Australia \\ Department of Mechanical Engineering, University of Zakho, Kurdistan Region, Iraq \\ *Corresponding author E-mail: raidalnuaimi@yahoo.com
}

\begin{abstract}
This paper investigates the effect of adding a liquid-suction heat exchanger on the performance of a mechanical refrigeration system using alternative refrigerants. Engineering Equation Solver (EES) was used to simulate a mechanical refrigeration system in two configurations: modified system with liquid-suction heat exchanger and system without liquid-suction heat exchanger. The results revealed that the liquidsuction heat exchanger has a significant effect on the system performance as it influences the subcooling and superheating temperatures. The results also showed that the highest value of the coefficient of performance (COP) was achieved by the modified system with refrigerant type R134a, COP was about 7\% and 12\% higher than that of refrigerants R600a and R22 respectively. It also presented that R600a has high response to increase the refrigerant effect when the liquid-suction heat exchanger is used. R600a is good alternative refrigerant and it can be used in the mechanical refrigeration system, but its COP is lower than that of R134a.
\end{abstract}

Keywords: Liquid-Suction Heat Exchanger; Alternative Refrigerant; Subcooling; Superheating

\section{Introduction}

Mechanical refrigeration system is one of the most usable refrigeration systems that can be used in domestic and commercial fields. It has four main parts: compressor, condenser, expansion valve and evaporator are connected in order together to build a close cycle [2]. Many studies have been done to modify and enhance the performance and energy consumption of the mechanical refrigeration system such as Bertsch and Groll [3], Wang and Zhang [4] and Jain, Arora [5]. While some studies investigated the refrigerants effect on the environment and its effects on system performance such as Llopis, Torrella [6], Llopis, Sánchez [7], and Aized and Hamza [8].

Using heat exchanger in the mechanical refrigeration system is one of the effective technique that can be used to improve the energy performance of the system [9]. Meanwhile, refrigerant type can also influence the system performance, so it is a big challenge to obtain matching between the system modification and refrigerant type. Refrigerant R134a is one of the alternative refrigerants that can be used to achieve good performance and exergy efficiency [10]. However, the system performance would be depending on the system modification such as using the liquid-suction heat exchanger which can improve the performance by $3 \%$ [11]. According to a previous study that carried out by Mohanraj, Muraleedharan [12], the R134a can be replaced by R43a in a basic system configuration to obtain high system performance. At the same time the R134a can be replace by R600a to get higher performance [13]. Mota-Babiloni, Haro-Ortuño [14] reported that using heat exchanger to modify the mechanical refrigeration system can increase the system cooling capacity up to $3 \%$ when the R134a is used as a working fluid. There are many techniques that can be used to modify the mechanical refrigeration system but using the heat exchanger technique is much effective and efficient [15]. The liquid-suction heat exchanger is commonly used in mechanical refrigeration system as it is ensure the system operation and increase the system performance [16]. Many studies have been carried out to investigate the effect of liquid-suction heat exchanger on the mechanical refrigeration system and compared it with different modification techniques such as Sunardi, Martin [1], Vaghela [17], Prayudi and Diantari [18] , and Hermes [19]. However, there is insufficient information about the system performance when the liquid-suction heat exchanger is used to compare the performance of the alternative refrigerants. Therefore, this paper investigates the performance of the alternative refrigerants R600a and R134a when the liquid-suction heat exchanger is used as a modification technique to improve the system performance.

\section{Model development}

Figure 1 illustrates the schematic diagram for the modified mechanical refrigeration system using liquid-suction heat exchanger technique, and it also presents the p-h (pressure-enthalpy) diagram for the cycle [1]. The p-h diagram shows the effect of the liquid-suction heat exchange on the suction temperature (superheat temperature) which represent the superheating in the cycle. The p-h diagram also presents the effect of the liquid-suction heat exchange on the sub-cool temperature which represent the subcooling. 
(A)

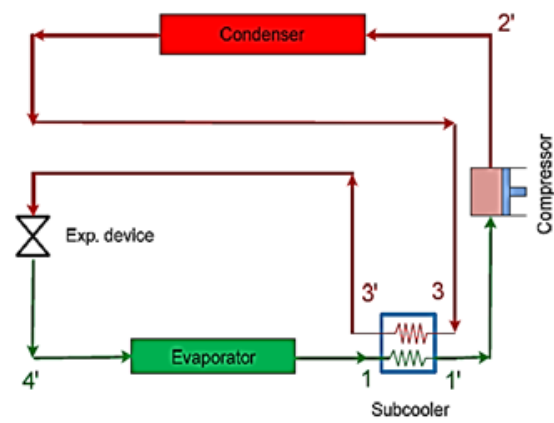

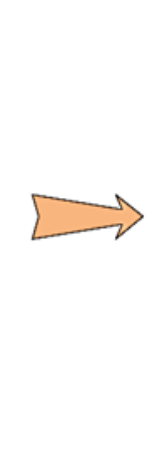

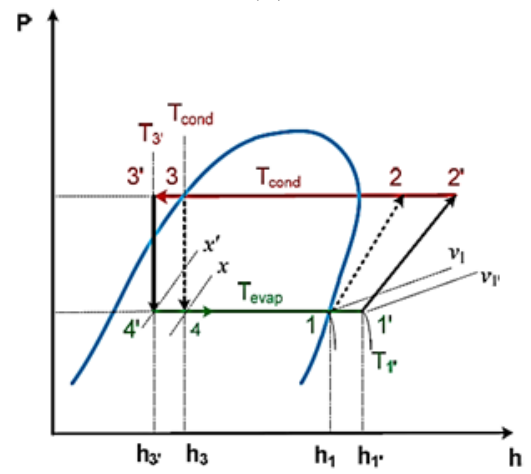

(B)

Fig. 1: Schematic Diagram: (A) Mechanical Refrigeration System Using Liquid-Suction Heat Exchanger, (B) P-H Diagram of the System [1].

The liquid-suction heat exchanger is installed across the suction and liquid lines to provide an effective function such as subcooling for the condensed refrigerant, boiling liquid of refrigerant which is located in the suction line and prevent liquid refrigerant entering the reciprocating compressor, and reducing the flash gas in the liquid line to ensure maximum capacity for the thermostatic expansion valve.

\subsection{Thermodynamic analysis for superheating}

Figure 2 presents the superheating effect on the mechanical refrigeration system on $\mathrm{p}$-h diagram when the pressure drop in the evaporator and condenser is neglected. From the Figure 2, the liquid-suction heat exchanger can increase the suction temperature from state (a) to state (1) which represents the superheating effect. The superheating can safe compressor from damage by preventing the refrigerant liquid droplets that may be flown with the gas from entering the suction line [20]. In this case the ideal refrigerate effect will be increased by adding the range of enthalpy change between stats (a) and (1).

$$
\operatorname{Re}_{\text {sup }}=\operatorname{Re}_{\text {ideal }}+\Delta \mathrm{h}_{\mathrm{a}-1}
$$

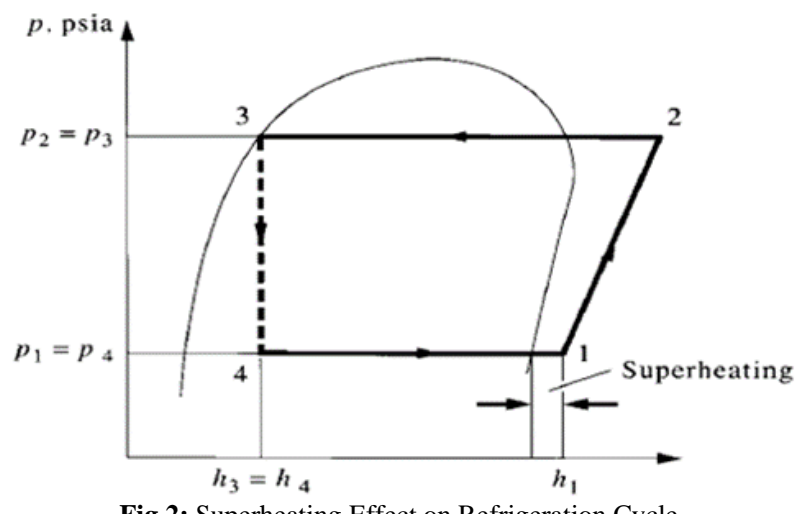

Fig 2: Superheating Effect on Refrigeration Cycle.

\subsection{Thermodynamic analysis for subcooling}

Figure 3 presents the subcooling effect on the ideal mechanical refrigeration system on p-h diagram. From the Figure 3, the liquid-suction heat exchanger can decrease the liquid refrigerant temperature at the exit of condenser from state (3) to state (3`) which represents the supercooling effect. The subcooling effect will increase the heat rejection by adding the range of enthalpy change between states (3) and (3`). Therefore, the enthalpy of the sub-cooled liquid refrigerant can be calculated as,

$\mathrm{h}_{\mathrm{SC}}=\mathrm{h}_{\mathrm{S}, \mathrm{CON}}-\mathrm{CP}_{\mathrm{Re}}\left(\mathrm{T}_{\mathrm{S}, \mathrm{CON}}-\mathrm{T}_{\mathrm{SC}}\right)$

Where

$\mathrm{h}_{\mathrm{S}, \mathrm{CON}}=$ enthalpy of saturated liquid refrigerant at condensing temperature $(\mathrm{J} / \mathrm{kg})$

$\mathrm{cp}_{\mathrm{Re}}=$ specific heat of liquid refrigerant at constant pressure $\left(\mathrm{J} / \mathrm{kg} .{ }^{\circ} \mathrm{C}\right)$

$\mathrm{T}_{\mathrm{S}, \mathrm{CON}}=$ saturated temperature of liquid refrigerant at condensing pressure $\left({ }^{\circ} \mathrm{C}\right)$

$\mathrm{T}_{\mathrm{SC}}=$ temperature of subcooled liquid refrigerant $\left({ }^{\circ} \mathrm{C}\right)$ 


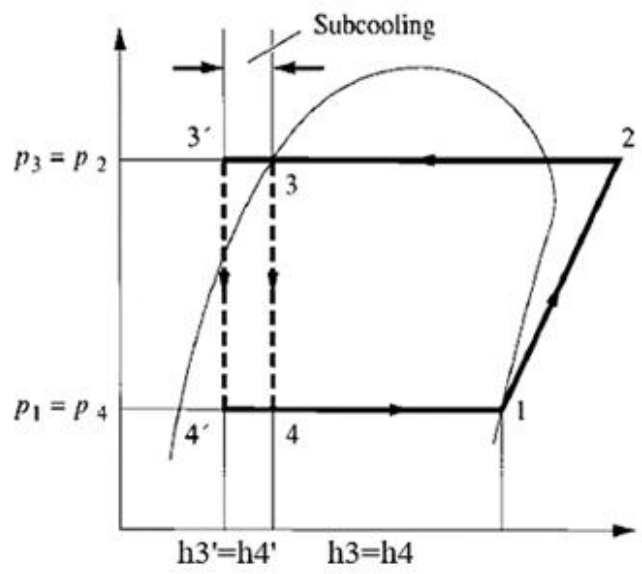

Fig 3: Sub-Cooling Effect on Refrigeration Cycle.

From the Figure 3, the subcooling also increase the refrigerant effect by the range of enthalpy change between states (4`) and (4) [21]. Therefore, the total refrigerant effect due to adding the liquid-suction heat exchanger will be the summation of the ideal refrigerant effect plus the enthalpy change in ranges (a-1) and (4-4) as follows,

$$
\begin{aligned}
& \operatorname{Re}_{\text {LSHE }}=\operatorname{Re}_{\text {ideal }}+\Delta \mathrm{h}_{\mathrm{a}-1}+\Delta \mathrm{h}_{4^{`}-4} \\
& \operatorname{Re}_{\mathrm{LSHE}}=\mathrm{Q}_{\text {evap }}=\mathrm{h}_{1}-\mathrm{h}_{4} .
\end{aligned}
$$

The total heat rejection from the cycle and as presented in Figure 1, will be estimated as follows,

$\mathrm{Q}_{\mathrm{R}-\mathrm{LSHE}}=\mathrm{h}_{2} \cdot \mathrm{h}_{3}$

Then the coefficient of performance (COP) of the system after adding the liquid-suction heat exchanger can be calculated as

$$
\mathrm{COP}=\frac{\text { Refrigerant effect }}{\text { Net.of supplied energy }}=\frac{\mathrm{Q}_{\text {evap }}}{\mathrm{W}_{\text {net }}}=\frac{\mathrm{h}_{1}-\mathrm{h}_{4}}{\mathrm{~h}_{2}-\mathrm{h}_{1}}
$$

Engineering equation solver (EES) was used to solve set of equations to obtain the enthalpies at all pointes on the p-h diagram in Figure 1 (b) based on the thermodynamic properties of the refrigerant. Some assumptions were applied to determine the performance of the modified mechanical refrigeration system using the liquid-suction heat exchanger: the system under steady state condition, heat transfer in pipes and compressor is neglected, and pressure drop is neglected. Range of operating conditions were used to cover wide range of operations. Alternative refrigerants R600a and R134a were used as a working fluid to be compared with the R22.

\section{Results}

All the results were obtained from EES after multiple runs using wide range of operating conditions and different refrigerants which were defined as R600a, R134a, and R22. Two system were modeled in the EES: modified system with liquid-suction heat exchanger, and nonmodified system without liquid-suction heat exchanger. This section will present and discuss the EES results for the modified and nonmodified systems.

\subsection{Effect of subcooling.}

Figure 4 shows the effect of liquid-suction heat exchanger on sub-cooling at different condenser pressure and different refrigerants. The liquid-suction heat exchanger improves the sub-cooling for three types of refrigerants; R22, R134a and R600a. However, higher value of the sub-cool temperature was achieved by R600a. The results have same trend and behavior compared with that from literature such as Dalkilic, Agra [21] and Lee and Su [22].

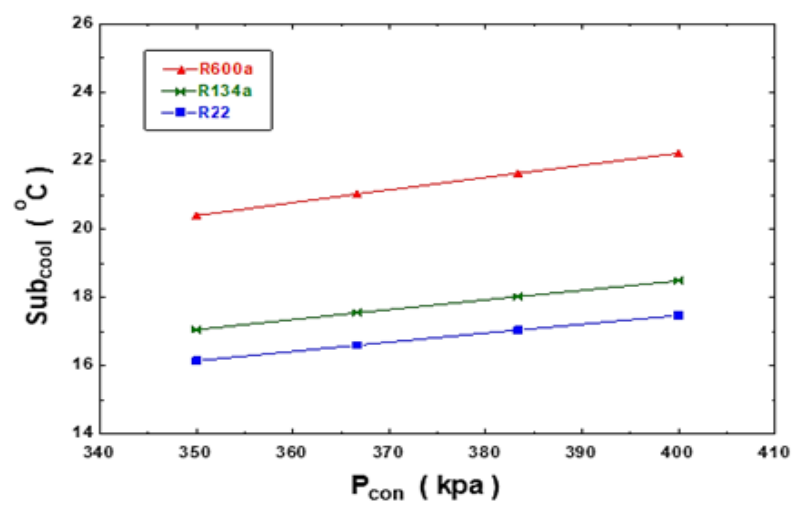

Fig. 4: Effect of Liquid-Suction Heat Exchanger on Superheating at Different Condenser Pressure and Different Refrigerants. 


\subsection{Effect of superheating}

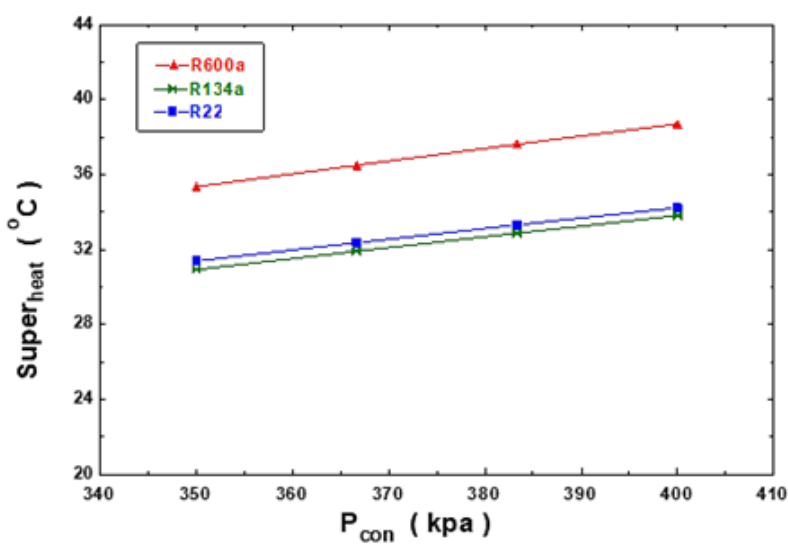

Fig. 5: Effect of Liquid-Suction Heat Exchanger on Superheating at Different Condenser Pressure and Different Refrigerants.

Figure 5 shows the effect of liquid-suction heat exchanger on superheating at different condenser pressure and different refrigerants. The liquid-suction line heat exchanger effectively increased the superheat temperature in the suction line. That is very useful to protect the compressor by preventing the liquid of refrigerant from entering the compressor, so the liquid drops would be evaporated due to the energy transfer between the hot liquid line and suction line in the liquid-suction heat exchanger. The Figure 5 also shows that the higher value of the super heat temperature was achieved by R600a and achieved better performance. The results were compared with that from the literature such as that in Feng, Kai [23] for R600a and Gill and Singh [24] for the R134a, same trend and behavior were obtained.

\subsection{Comparison between non-modified and modified system}

A comparison between the non-modified system which does not have the liquid-suction heat exchanger and modified system which has the liquid-suction heat exchanger has been done to present the differences in Refrigerant Effect (RE) and Coefficient of Performance (COP). Figures 6 and 7 presents the effect of the liquid-suction heat exchanger on the refrigerant effect in the modified and non-modified systems respectively using different refrigerants. From Figure 6, the R600a achieved highest value of refrigerant effect which was about $250 \mathrm{~kJ} / \mathrm{kg}$ when the condenser pressure was $350 \mathrm{kPa}$. However, at the same operating conditions the R600a achieved higher than $250 \mathrm{~kJ} / \mathrm{kg}$ in the modified system. By using the liquid-suction heat exchanger R600a recorded higher refrigerant effect which was $350 \mathrm{~kJ} / \mathrm{kg}$ when the condenser pressure was $350 \mathrm{kPa}$ as shown in Figure 7. The results compared with that from literature such as that in Klein, Reindl [16] and Prayudi, Nurhasanah [25].

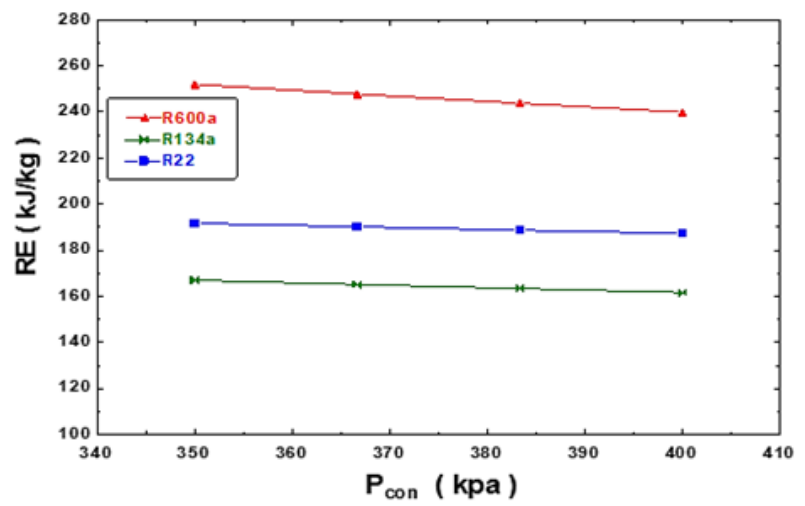

Fig. 6: Effect of Liquid-Suction Heat Exchanger on Refrigerant Effect at Different Condenser Pressure and Different Refrigerants in the Non-Modified System.

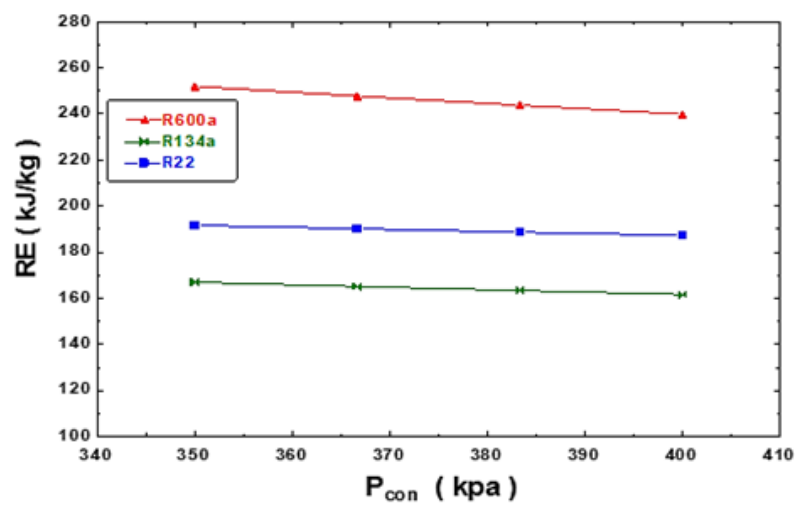

Fig. 6: Effect of Liquid-Suction Heat Exchanger on Refrigerant Effect at Different Condenser Pressure and Different Refrigerants in the Non-Modified System. 


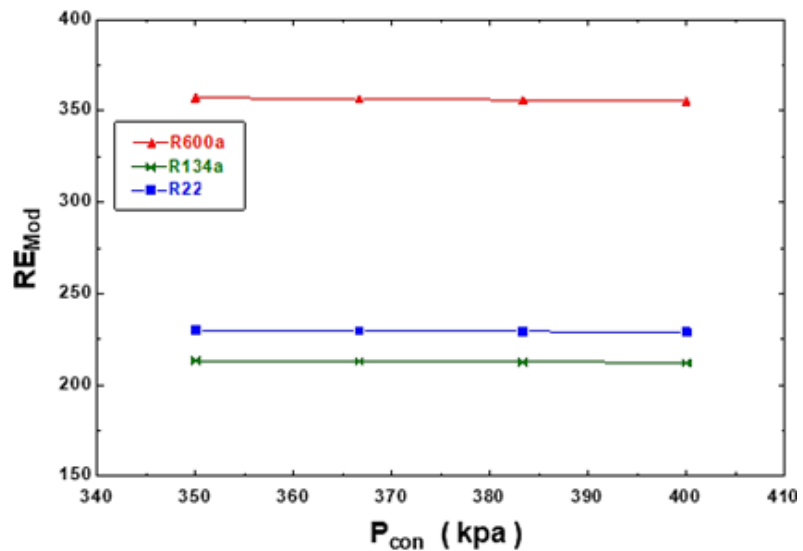

Fig. 7: Effect of Liquid-Suction Heat Exchanger on Refrigerant Effect at Different Condenser Pressure and Different Refrigerants in the Modified System.

Figure 8 summarize the comparison of COP between the system with liquid-suction heat exchanger and system without liquid-suction heat exchanger at different operating condition using R600a, R134a and R22. The Figure shows that the highest value of COP was achieved by the modified system using R134a which is about 7\% and 12\% higher than that of R600a and R22 respectively.

Indeed, the effect of adding the liquid-suction heat exchanger is very significant and it can increase the COP efficiently compared with that system without liquid-suction heat exchanger. The COP can be improved and enhanced up to $20 \%$ based on the refrigerant type and operating conditions. The R600a is good replacement for other refrigerants but it has lower COP compared with R134a due to its thermodynamic properties as mentioned in literature such as Qureshi and Bhatt [26] and Adelekan, Ohunakin [27].



Fig. 8: Comparison of COP Between the System with Liquid-Suction Heat Exchanger and System Without Liquid-Suction Heat Exchanger at Different Operating Condition Using R600a, R134a and R22.

\section{Conclusion}

The effect of adding the liquid-suction heat exchanger in a mechanical refrigeration system was investigated theoretically using different refrigerants. Engineering equation solver (EES) was used to solve set of equations based on the thermodynamic properties of the working fluid. The results were compared with the literature and obtained same trend and behavior. The results revealed that the modern refrigerant R134a has 7\% higher COP compared with R600a and 12\% compared with R22. The COP can be improved and enhanced up to $20 \%$ based on the refrigerant type and operating conditions when the liquid-suction heat exchanger used. It also presented that R600a has high response to increase the refrigerant effect when the liquid-suction heat exchanger used. R600a is good alternative refrigerant and it can be used in mechanical refrigeration system, but its COP is lower than that of R134a. The superheating and subcooling effect were recorded with high value when the R600a was used in modified and no-modified systems.

\section{Acknowledgement}

The author thanks the University of Southern Queensland and University of Zakho for the support that provided to complete this research.

\section{References}

[1] Sunardi, C., et al., Performance improvement using subcooling on freezer with $R-22$ and R290 as refrigerant for variousambient temperatures. ARPN Journal of Engineering and Applied Sciences, 2016. 11(2): p. 931-934.

[2] Matsumoto, T., T. Chino, and M. Kusama, Heat Exchanger for Refrigeration Cycle. 2014, US Patent 20,140,311,181.

[3] Bertsch, S.S. and E.A. Groll, Two-stage air-source heat pump for residential heating and cooling applications in northern U.S. climates. International Journal of Refrigeration, 2008. 31(7): p. 1282-1292. https://doi.org/10.1016/j.ijrefrig.2008.01.006.

[4] Wang, G.-B. and X.-R. Zhang, Thermoeconomic optimization and comparison of the simple single-stage transcritical carbon dioxide vapor compression cycle with different subcooling methods for district heating and cooling. Energy Conversion and Management, 2019. 185: p. 740-757. https://doi.org/10.1016/j.enconman.2019.02.024.

[5] Jain, G., A. Arora, and S. Gupta, Performance characteristics of a two-stage transcritical N2O refrigeration cycle with vortex tube. International Journal of Ambient Energy, 2020. 41(5): p. 491-499. https://doi.org/10.1080/01430750.2018.1472646. 
[6] Llopis, R., et al., Performance evaluation of R404A and R507A refrigerant mixtures in an experimental double-stage vapour compression plant. Applied Energy, 2010. 87(5): p. 1546-1553. https://doi.org/10.1016/j.apenergy.2009.10.020.

[7] Llopis, R., D. Sánchez, and R. Cabello, Alternative refrigerants for the primary circuit of an indirect commercial refrigeration cascade system. 2018.

[8] Aized, T. and A. Hamza, Thermodynamic Analysis of Various Refrigerants for Automotive Air Conditioning System. Arabian Journal for Science and Engineering, 2019. 44(2): p. 1697-1707. https://doi.org/10.1007/s13369-018-3646-8.

[9] Llopis, R., et al., Experimental evaluation of an Internal Heat Exchanger in a CO 2 subcritical refrigeration cycle with gas-cooler. Applied Thermal Engineering, 2015. https://doi.org/10.1016/j.applthermaleng.2015.01.040.

[10] Siva Reddy, V., N. Panwar, and S. Kaushik, Exergetic analysis of a vapour compression refrigeration system with R134a, R143a, R152a, R404A, R407C, R410A, R502 and R507A. Clean Technologies and Environmental Policy, 2012. 14(1): p. 47-53. https://doi.org/10.1007/s10098-011-0374$\underline{0}$.

[11] Devecioğlu, A.G. and V. Oruç, Improvement on the energy performance of a refrigeration system adapting a plate-type heat exchanger and lowGWP refrigerants as alternatives to R134a. Energy, 2018. 155: p. 105-116. https://doi.org/10.1016/j.energy.2018.05.032.

[12] Mohanraj, M., C. Muraleedharan, and S. Jayaraj, A review on recent developments in new refrigerant mixtures for vapour compression-based refrigeration, air-conditioning and heat pump units. International Journal of Energy Research, 2011. 35(8): p. 647-669. https://doi.org/10.1002/er.1736.

[13] Agrawal, N., S. Patil, and P. Nanda, Experimental Studies of a Domestic Refrigerator Using R290/R600a Zeotropic Blends. Energy Procedia, 2017. 109: p. 425-430. https://doi.org/10.1016/j.egypro.2017.03.051.

[14] Mota-Babiloni, A., et al., Experimental drop-in replacement of R404A for warm countries using the low GWP mixtures R454C and R455A. International Journal of Refrigeration, 2018. 91: p. 136-145. https://doi.org/10.1016/j.ijrefrig.2018.05.018.

[15] Lord, R.G. and C. Rahhal, Internal liquid suction heat exchanger. 2017, Google Patents.

[16] Klein, S., D. Reindl, and K. Brownell, Refrigeration system performance using liquid-suction heat exchangers. International Journal of Refrigeration, 2000. 23(8): p. 588-596. https://doi.org/10.1016/S0140-7007(00)00008-6.

[17] Vaghela, J., Experimental Evaluation of an Automobile Air-Conditioning System with and without Liquid Suction Heat Exchanger. SAE International Journal of Passenger Cars-Mechanical Systems, 2016. 9(2016-01-9110): p. 1279-1288. https://doi.org/10.4271/2016-01-9110.

[18] Prayudi, N. and R.A. Diantari. The effect the effectiveness of the liquid suction heat exchanger to performance of cold storage with refrigerant R22, R404A and R290/R600a. in American Institute of Physics Conference Series. 2017. https://doi.org/10.1063/1.4968320.

[19] Hermes, C.J., Heat transfer and pressure drop trade-offs in liquid-to-suction heat exchangers. International Journal of Refrigeration, 2019. 104: p. 496-500. https://doi.org/10.1016/j.ijrefrig.2019.05.011.

[20] Getu, H.-M. and P.K. Bansal, Simulation Model of a Low-Temperature Supermarket Refrigeration System. HVAC\&R Research, 2006. 12(4): p. 1117-1139. https://doi.org/10.1080/10789669.2006.10391454.

[21] Dalkilic, A., et al., Comparison of frictional pressure drop models during annular flow condensation of R600a in a horizontal tube at low mass flux and of R134a in a vertical tube at high mass flux. International Journal of Heat and Mass Transfer, 2010. 53(9): p. 2052-2064. https://doi.org/10.1016/j.ijheatmasstransfer.2009.12.051.

[22] Lee, Y. and C. Su, Experimental studies of isobutane (R600a) as the refrigerant in domestic refrigeration system. Applied Thermal Engineering, 2002. 22(5): p. 507-517. https://doi.org/10.1016/S1359-4311(01)00106-5.

[23] Feng, C., et al., Investigation of the heat pump water heater using economizer vapor injection system and mixture of R22/R600a. International Journal of Refrigeration, 2009. 32(3): p. 509-514. https://doi.org/10.1016/j.ijrefrig.2008.06.012.

[24] Gill, J. and J. Singh, Experimental analysis of R134a/LPG as replacement of R134a in a vapor-compression refrigeration system. International Journal of Air-Conditioning and Refrigeration, 2017. 25(02): p. 1750015. https://doi.org/10.1142/S2010132517500158.

[25] Prayudi, R. Nurhasanah, and R.A. Diantari. The effect the effectiveness of the liquid suction heat exchanger to performance of cold storage with refrigerant R22, R404A and R290/R600a. in AIP Conference Proceedings. 2017. AIP Publishing LLC. https://doi.org/10.1063/1.4968320.

[26] Qureshi, M.A. and S. Bhatt, Comparative Analysis of COP using R134a \& R600a Refrigerant in Domestic Refrigerator at steady state condition. International Journal of Science and Research (IJSR), 2014. 3(12).

[27] Adelekan, D., et al., Experimental Investigation of a Vapour Compression Refrigeration System with 15nm TiO2-R600a Nano-Refrigerant as the Working Fluid. Procedia Manufacturing, 2019. 35: p. 1222-1227. https://doi.org/10.1016/j.promfg.2019.06.079. 